\title{
Perils, paradigms, and possibilities: A commentary and recommendation on re-evaluating racial disparities in cardiac surgery
}

Zachary Enumah ${ }^{1}$ and Ahmet Kilic ${ }^{1}$

${ }^{1}$ The Johns Hopkins Hospital

September 25, 2021

\section{Hosted file}

Perils paradigms and possibilities commentary_final.docx available at https://authorea. com/users/436461/articles/538760-perils-paradigms-and-possibilities-a-commentary-andrecommendation-on-re-evaluating-racial-disparities-in-cardiac-surgery 